INTERNATIONAL JOURNAL OF RESEARCHES IN BIOSCIENCES, AGRICULTURE AND TECHNOLOGY (c) VISHWASHANTI MULTIPURPOSE SOCIETY (Global Peace Multipurpose Society) R. No. MH-659/13(N) www.vmsindia.org

\title{
ULTRASONIC STUDIES OF AMINO ACID IN AQUEOUS SALT SOLUTION AT DIFFERENT TEMPERATURES
}

\author{
V. A. Giratkar ${ }^{*}$, R. B. Lanjewar ${ }^{2}$ and S. M. Gadegone ${ }^{3}$ \\ ${ }^{1}$ Departme nt of Chemistry, Sardar Patel College, Chandrapur, 442403, Maharas htra, India \\ ${ }^{2}$ Departme nt of Chemistry, M.P. De o Memorial Science College, Nagpur, Maharashtra, India \\ 3Department of Chemistry, Kamla Nehru College, Nagpur, Maharashtra, India \\ giratkar.vandana@gmail.com
}

\begin{abstract}
Densities, viscosities and ultrasonic velocities of an amino acid L-Serine at four diffe rent temperatures $288.15,293.15,298.15$ and $303.15 \mathrm{~K}$ for various concentrations $(0.02$ to 0.12$) \mathrm{mol} \mathrm{dm}-3$ in $2 \%$ of aqueous electrolytic solution have been measured. These measurements have been use d to evaluate some important thermo-acoustic parameters such as Rao's constant (R), Wada's constant (W), molecular radius (ro), absorption coefficient (a/f2) and relaxation strength. The results are interpreted in terms of molecular in te ractions between the components of the mixture.
\end{abstract}

Keywords: L-Serine, Ultra sonic velocity, amino acids, aque ous electrolytic solution, molecular interactions

\section{INTRODUCTION}

Ultrasound waves are similar to sound waves, where both travel through a medium. Ultrasonic is the science of acoustics and the technology of sound. The frequency range of ultrasonic waves is greater than $20 \mathrm{kHz}$ up to several $\mathrm{MHz}$, which is beyond the audible limit. Ultrasonic studies at low amplitude provide valuable information regarding the structure and interactions taking place in pure liquids and multi component liquid mixtures. Ultrasonic velocity depends on material density and elasticity. Ultrasonic method has become a powerful tool in providing information regarding the physico-chemical properties of liquid system [1-5].

Amino acids are the fundamental, structural units of proteins, peptides and certain types of hormones and antibiotics participate in all the physiological processes of a living cell. Protein cannot exist without the correct combination of amino acids. Most of the studies on amino acids and biomolecules have been carried out in pure and mixed aqueous solutions [6-10].

L-serine is a non-essential amino acid occurring in natural form as the Lisomer. Serine is functionally important in many proteins. With an alcohol group, serine is needed for the metabolism of fats, fatty acids, and cell membranes, muscle growth and healthy immune system. It also helps in the production of antibodies [11]. Serine is used as a natural moisturizing agent in some cosmetics and skin care products. L-Serine, D-serine, Glycine and folate metabolism are very important for the development and the proper function of the central nervous system [12].

\section{MATERIALS AND METHODS}

The amino acid L-Serine [CAS No. 56-45-1, molecular weight 105.09] used in the present work is of analytical reagent grade with $99 \%$ purity obtained from HIMEDIA India Ltd. Double distilled water was used for the preparation of all the fresh solutions under study. Measurements of weights were done using digital balance having an accuracy of $\pm 0.1 \mathrm{mg}$. A digital constant temperature water bath having an accuracy of $\pm 0.1 \mathrm{~K}$ was used for measuring the densities, viscosities and velocities of solutions under study at desired temperatures. A stock solution of $2 \%$ aqueous $\mathrm{NaCl}$ was prepared by using double distilled wate $r$ and it was used as a solvent for the preparation of L-Serine solution of different concentrations. The densities of aqueous solvent and solution of different concentration $(0.02 \mathrm{M}$ to $0.12 \mathrm{M})$ at differe nt temperature range $\mathrm{T}=(288.15$ to 303.15$) \mathrm{K}$ were measured by specific gravity bottle by relative measurement method with accuracy of $\pm 0.1 \mathrm{~kg} \cdot \mathrm{m}^{-3}$. The ultrasonic velocity of solvent and solution of different concentration at different te mperature range $(288.15 \mathrm{~K}$ to $303.15 \mathrm{~K})$ was measured by using digital ultrasonic interferometer operating at frequency $2 \mathrm{MHz}$ (VI Microsystems Pvt. Ltd. Perungudi, Chennai) with an accuracy of $\pm 0.1 \%$. The interfe rometer was calibrated by measuring the speed of sound in double distilled water. The temperature of solution was kept constant during each measurement. The viscosity of solvent and all the solutions of LSerine were measured using Ostwald's viscometer owing to its versatility. The 
accuracy of the viscosity measurement was

$\pm 0.1 \%$.

\section{PHYSICAL PARAMETERS}

The following the rmodynamic parameters are evaluated by using experimentally measured parameters such as density, viscosity and ultrasonic velocity. The molecular interactions are explained in terms of these parameters.

Rao's constant $(\mathrm{R})$

$\mathrm{R}=\mathrm{V}_{\mathrm{m}} \mathrm{U}^{1 / 3}$

Where, $\mathrm{V}_{\mathrm{m}}$ is molar volume

Wada's constant (W)

$\mathrm{W}=\beta_{\mathrm{a}}{ }^{1 / 7} \mathrm{~V}_{\mathrm{m}}$

Molecular radius

$\left.r_{o}=\left(3 M_{e f f} / 16 \pi \rho V_{m}\right)^{1 / 3}\left[1-\left(\gamma R g T / M_{e f f} U^{2}\right)\left(\frac{M_{\text {eff }} U^{2}}{3 \gamma R g T}\right)+1\right)-1\right)^{1 / 3}$

Absorption coefficient

$\left(\frac{\alpha}{\mathrm{f}^{2}}\right)=\frac{8 \eta \pi^{2}}{3 \rho \mathrm{U}^{3}}$

Relaxation strength

$$
r=1-\left(\frac{U}{U_{\infty}}\right)^{2}
$$

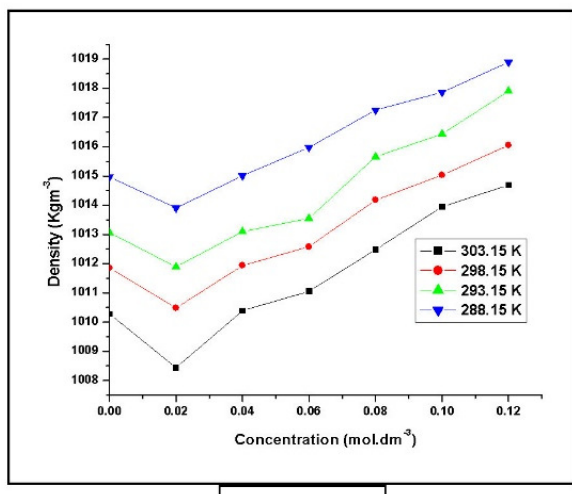

Fig.1 (a)

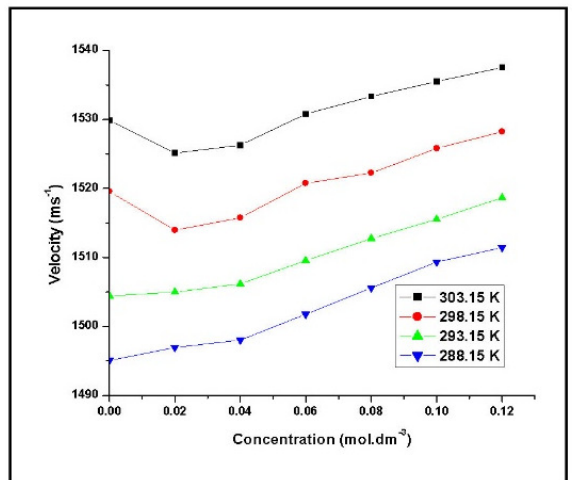

Fig.1 (c)

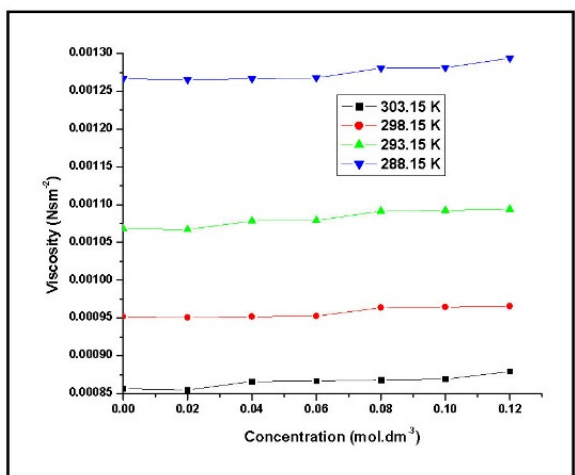

Fig.1 (b)

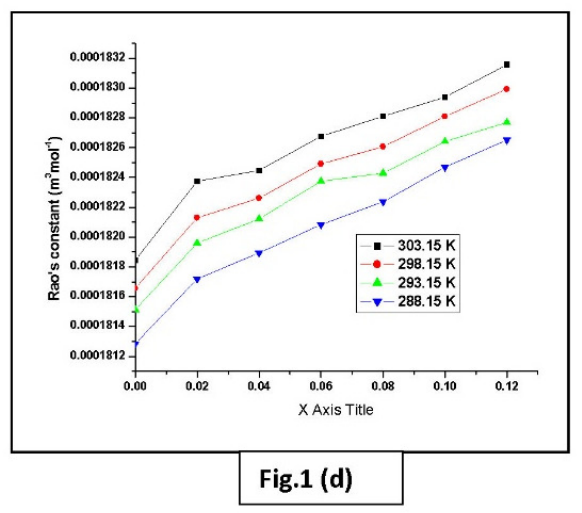



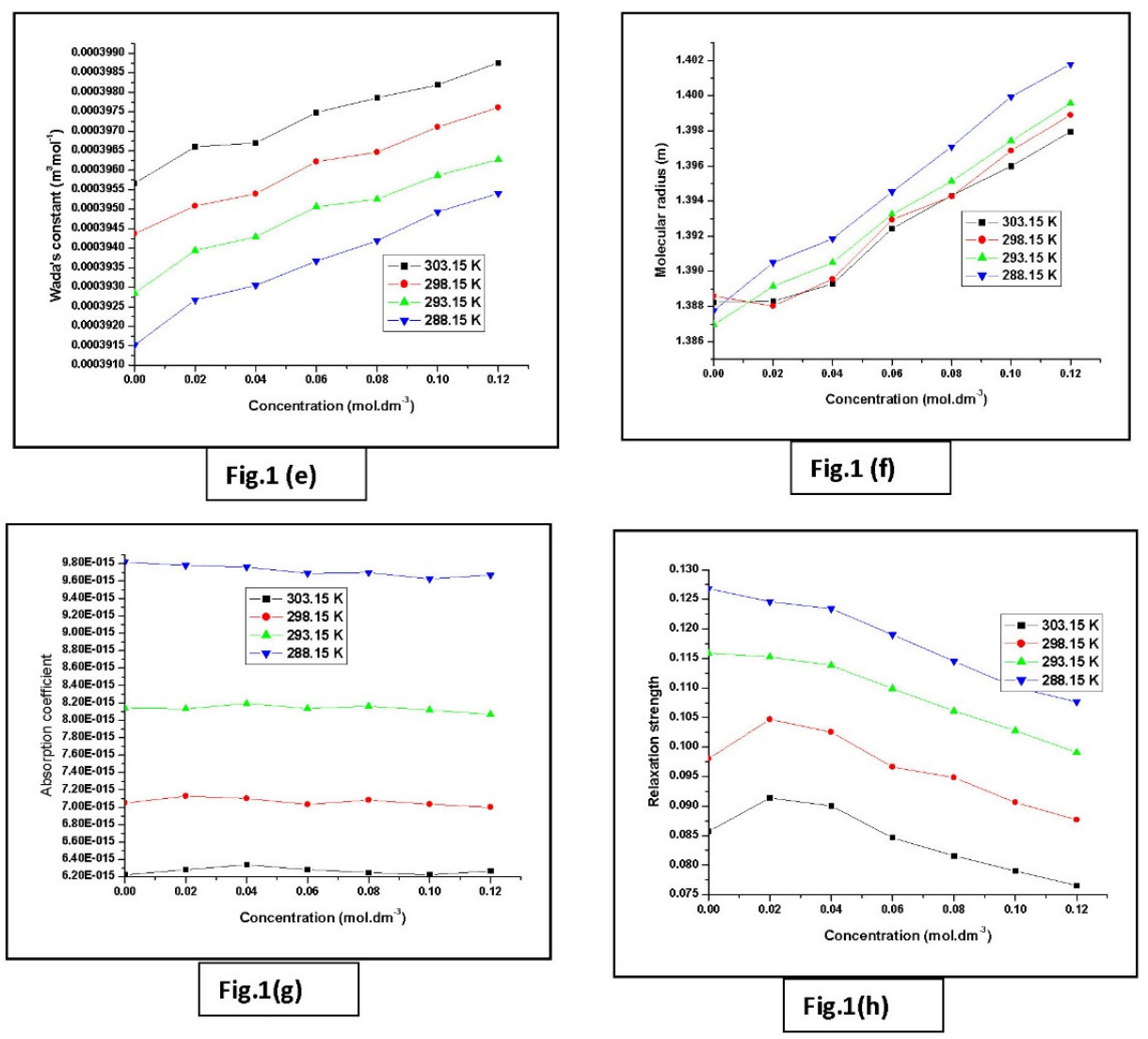

\section{RESULT AND DISCUSSION}

The variation of experimentally measured values of density, viscosity and ultrasonic velocity and the various the rmoacoustic parame te rs of L-Serine in $2 \%$ aqueous solution of sodium chloride of different concen tration (0.02 to 0.12$) \mathrm{mol} \mathrm{dm}^{-}$ 3 at diffe re nt temperature range $\mathrm{T}=(288.15$, $293.15,298.15$ and 303.15$) \mathrm{K}$ are as given in fig. $1 \mathrm{a}-\mathrm{h}$.

Density of the L-Serine aqueous $2 \%$ $\mathrm{NaCl}$ solution in the present investigation increases with molar concentration at constant temperature and as usual decreases with temperature at certain concentration as depicted in Fig.1 (a). No abnormal changes are observed in the variation of density. This shows that density has no influence on molecular association or dissociation and the variation observed is due to increase of L-Serine solute particles in aqueous $2 \% \mathrm{NaCl}$ solvent and nothing else. Similar observations are made by various researchers [13-14].The vis cosity variation of L-Serine aqueous $2 \% \mathrm{NaCl}$ solution is as shown in Fig. 1(b). Amino acids when dissolved in aqueous solution forms zwitterions having $\mathrm{NH}_{4}{ }^{+}$and $\mathrm{COO}^{-}$groups at

the two ends of the molecule. The $\mathrm{Na}^{+}$ions furnished by the salt get attracted towards the negative end and $\mathrm{Br}^{-}$ions of the salt towards the positive end of zwitterions. Also the dipoles of the water get strongly aligned to the cations and anions of the salt as well as towards the zwitterions by electrostatic forces. These interactions lead to the formation of cohesive forces and intermolecular hydrogen bonding in the present system upon increment of the solute in the solvent. The decreasing trend in viscosity of the solution with the rise in temperature is due to increase in molecular agitation which results in weakening of cohesive forces among the components of solution [17]. Ultrasonic velocity is an important parameter which provides information regarding nature and extent of molecular interaction and is greatly affected by the concentration and the temperature. It depends upon the change in elastic properties of liquid solution during its propagation. Ultrasonic velocity of the solution increases with concentration as well as with te mperature as shown in Fig.1(c). As the concentration increases compressibility of the solution decreases and hence 
ultrasonic velocity increases indicating clearly rise in solute-solvent interactions resulting in the greater molecular association through hydrogen bonding among the compone nts in the solution [18].

The values of Rao's constant and Wada constant [Fig.1 (d) and Fig.1 (e)] of L-serine solution shows increase in the ir respective values due to increase in concentration. These variations leads to conclusion that medium is closely packed and favors the increase in solute-solvent interactions. The orders of these constant is found to be same as compared to the literature data [21-23]. Most of the physiochemical properties of matter depend on size of the molecules. From Fig.1 (f), it is observed that molecular radius of L-se rine solution increases with increase in concentration and decreases with incre ase in temperature. Incre ase in molecular radius indicates greater association among components due to increase in intermolecular hydrogen bonding and dispersion forces between solute and solvent molecules. As temperature increases, molecular radius also increases because as temperature increases hydrogen bonding and dispersion forces between the solute and solvent molecules become weak.

When ultrasound wave moves through matter, continuous loss of energy takes place which is called attenuation. Several factors contribute to this reduction in energy. One of the most significant is the absorption of the ultrasound energy by the material and its conversion into heat. When ultrasound waves interact with particles of the medium, a part of the ultrasonic ene rgy is converted into heat due to viscosity and the rmal conduction. From Fig.1 (g), it is found that absorption coefficient shows very slight variation with composition but large variation with temperature. As temperature increases absorption coefficient decreases. This is because at high temperature, the thermal motion of the molecules increases and intermolecular forces of attraction becomes weak. Hence due to weak intermolecular forces, less absorption of sound wave will occur. Hence absorption coefficient decreases with increase in temperature.

Relaxation strength is directly related to adiabatic compressibility. If by the addition of solute to a solvent, the values of relaxation strength decreases then it indicates solute-solvent interaction in the system. This happens because of formation of complex [24] by solvent molecules around solute molecules. It is observed from fig $1(\mathrm{~h})$, that relaxation stre ngth of $\mathrm{L}$-s erine solutions decreases with increase in concentration which suggest the greater molecular association between solute and solvent molecules.

Relaxation strength depends on the factor [1-U/Uo]. Here U indicates ultrasonic velocity of solution and Uo is constant. As the values of ultrasonic velocity increases with increase in te mperature, relaxation strength values decreases with increases in tempe rature.

\section{CONCLUSION}

It is concluded that strength of intermolecular interaction increases with increase in concentration of L-Serine which indicates solu te-solvent in te ractions.

\section{REFERENCE}

[1] Dash, A. K. and Paikaray, R. (2014): Acoustical study in binary liquid mixture containing dimethyl acetamide using ultrasonic and viscosity probes. Der. Chem. Sinica., vol 5(1): Pp81-88.

[2] Palani, R., Saravanan, S., Kumar, R. (2009): Ultrasonic studies on some te rnary organic liquid mixtures at 303, 308 and 313K. Rasayan J. Chem., vol 2(3): Pp 622629.

[3] Paikaray, R. and Mohanty, N. (2013): Evaluation of thermodynamical acoustic parameters of binary mixture of DBP with toluene at $308 \mathrm{~K}$ and at differe $n t$ fre quencies. Res. J. Chem. Sci. vol 3(5): Pp 71-82.

[4] Mistry A. A., Bhandakkar, V. D. and Chimankar, O. P. (2012): Acoustical studies on ternary mixture of toluene in cyclohexane $\&$ nitrobenzene at $308 \mathrm{~K}$ using ultrasonic technique. J. Chem. and Pharm. Res., vol 4(1): Pp 170-174.

[5] Thirumaran, S. and Karthikeyan, N. (2014): Thermo-acoustical studies on interio nic in te ractions of some a-amino acids in aqueous sucrose solution at varying mass percentages. Orient. J. Chem., vol 30(1): Pp 133-148.

[6] Palani, R. and Geetha, A. (2007): Acoustical and the rmodynamical studies of L-serine, L-glutamine and L-asparagine in aqueous D-glucose solutions at 298.15 K. Res. J. Phys., vol 1: Pp 82-89.

[7] Kumar, H. and Kaur, K. (2013): Densities and speeds of sound of L-serine with aqueous solutions of antibacterial drugs at 
different te mperatures. J. Chem. Eng. Data., vol 58(2): Pp 203-208.

[8] Kumar, H. and Kaur, K. (2013): Densities and speeds of sound of L-serine with aqueous solutions of antibacterial drugs at different temperatures. J. Chem. Eng. Data. Vol 58(2): 203-208.

[9] Palani, R., Balakrishnan, S. and Arumugam, G. (2011): Ultrasonic studies of amino acids in aqueous sucrose solution at different temperatures. J. Phys. Sci., vol 22(1): Pp 131-141.

[10] Kannappan, A. N. and Palani, R. (2007): Ultrasonic investigations of amino acids with aqueous dime thyl formamide. Ind. J. Chem., vol 46(A): Pp 54-59.

[11] http://www.nutritional-supple mentshealth-guide.com/serine.html

[12] http:/ / aminoacids tu dies.org/1-se rine /

[13] Malimath, G. H. and Maridevarmath, C. V. (2016): Study of molecular inte ractions in antihis tamine drug cinnarizine and benzene at different temperatures. Der Pharma Chem., vol 8(2): Pp 92-97.

[14] Gomez-Diaz, D. and Navaza, J. M. (2007): Speed of Sound and Isentropic Compressibility of Aqueous Solutions of Pyrrolidine and Piperidine. J. Chem. Eng. Data., vol 52(3): Pp 889-891.

[15] Mirikar, S. A., Pawar, P. P. and Bichile, G. K. (2015): U1trasonic velocity, density and viscosity measurement of amino acid in aqueous electrolytic solutions at $308.15 \mathrm{~K}$. Amer. J. Pharm. and Pharma., vol2 (1): Pp 19-25.

[16] Patil, K. C. and Dudhe, C. M. (2015): Molecular interaction study of aqueous solution of an aminoglycoside antibiotic Neomycin at 298.15 to 308.15 K, Der Pharma Chemi., vol 7(12): Pp 219-226.
[18] Rao, N. P. and Verrall, R. (1987): Ultrasonic velocity, excess adiabatic compres sibility, a pparent molar volume, and apparent molar compressibility properties of binary liquid mixtures containing 2butoxye thanol. Can. J. Chem, vol 65: Pp 810816.

[19] Ravichandran, S. and Ramanathan, K. (2008): Molecular Interactions with Polyacrylamide in ethanolamine, die thanolamine, and triethanolamine solutions measured ultrasonically. PolymerPlastics Technology and Engineering. Vol 47 : Pp 169-173.

[20] Praharaj, M., Satapathy, A., Mishra, P. and Mishra, S. (2013): Ultra sonic analysis of intermolecular inte raction in the mixtures of benzene with $\mathrm{N}, \mathrm{N}$-dime thyl formamide and cyclohexane at different temperatures. J. Chem and Pharm. Res., vol 5(1): Pp 49-56.

[21] Mehra, R. and Malav, B. B. (2011): Acoustic, volu metric and vis co me tric studies of DL-alanine in aqueous galacto se solution in the presence of sodium chloride at 298, 308 and 318 K. Res. J. Pharma. Bio. and Chem. Sci., vol 2(3): Pp 709-719.

[22] Baluja, S., Solanki, A. and Kachhadia, N. (2010): Studies on thermodynamic properties of some imidazolinone derivatives in DMF at 308.15 K. Chin. J. Che. Eng., vol 18(2): Pp 306-311.

[23] Baluja, S. and Kachhadia, N. (2012): Density, viscosity and speed of sound in solutions of some imidazolinone derivatives in DMSO at 308.15 K. Int. J. Basic and Appl. Chem. Sci., vol 2(1): Pp 63-73.

[24] Baluja, S. and Karia, F. (200): A comparative study of ultrasonic velocity and allied parame te rs of ternary systems. J. Pure and Appl. Ultrasonics. vol 22(3): Pp 82-85. 